\title{
Cognitive control of feature bindings: evidence from children with autistic spectrum disorder
}

\author{
Sharon Zmigrod • Leo M. J. de Sonneville • \\ Lorenza S. Colzato $\cdot$ Hanna Swaab $\cdot$ Bernhard Hommel
}

Received: 9 February 2011 / Accepted: 23 November 2011 / Published online: 6 December 2011

(C) The Author(s) 2011. This article is published with open access at Springerlink.com

\begin{abstract}
Understanding how the brain integrates features from different domains that are processed in distinct cortical regions calls for the examination of integration processes. Recent studies of feature-repetition effects demonstrated interactions across perceptual features and action-related features: repeating only some features of the perception-action episode hinders performance. These partial-repetition costs point to the existence of temporary memory traces (event files). However, the principles and the constraints that govern the management of such traces are still unclear. Here, we investigated whether children with autistic spectrum disorder (ASD) differ from typically developing children in managing episodic memory traces. The results show that both groups integrate stimulus features along with action features, but children with ASD exhibit larger partial-repetition costs, suggesting lesser control and flexibility in updating episodic memory traces. The findings are discussed in the light of evidence for a central role of the dopaminergic system in cognitive integration, ASD, and cognitive control.
\end{abstract}

\section{Introduction}

Given that the primate cortex processes the various features of perceptual events and actions in distinct brain regions (e.g., DeYoe \& van Essen, 1988), it has been assumed that

S. Zmigrod · L. M. J. de Sonneville · L. S. Colzato · H. Swaab ·

B. Hommel

Leiden Institute for Brain and Cognition, Leiden, The Netherlands

S. Zmigrod ( $\square)$

Cognitive Psychology Unit, Leiden University,

Wassenaarseweg 52, 2333 AK Leiden, The Netherlands

e-mail: szmigrod@fsw.leidenuniv.nl the representations of these features need to be integrated into coherent episodic bindings (e.g., Hommel, 2004; Kahneman, Treisman, \& Gibbs, 1992). Evidence for the spontaneous integration of perceptual features comes from analyses of (interactions between) repetition effects. For instance, people not only respond faster to letters that they just saw in a preview display (a standard priming or repetition effect), but they are particularly fast if the repeated letter also appears in the same location (Kahneman et al., 1992). This suggests that processing a perceptual event induces the binding of the codes of its features, so that repeating the particular conjunction of features allows for particularly efficient processing.

Comparable observations have been made for auditory features (Mondor, Hurlburt, \& Thorne, 2003; Zmigrod \& Hommel, 2009), perceptual features from different sensory modalities (Zmigrod, Spapé, \& Hommel, 2009), and for perceptual and action features (Hommel, 1998). For instance, responding to object $\mathrm{A}$ by carrying out response $\mathrm{X}$ is easier after having paired $\mathrm{A}$ and $\mathrm{X}$, or the unrelated object $\mathrm{B}$ and action $\mathrm{Y}$, than after having responded differently to the same object $(\mathrm{A} \rightarrow \mathrm{Y}$ ) or responded similarly to a different object $(\mathrm{B} \rightarrow \mathrm{X})$. Apparently, then, a single pairing of a stimulus (feature) and a response is sufficient to create an episodic binding (an event file; Hommel, 1998) that interferes with partially, but not completely overlapping bindings. This suggests that repeating at least one (stimulus and/or response) feature leads to the retrieval of the just created binding, which interferes with current processing if that involves the reactivation of a previous (no longer valid) feature code (Hommel, 2004). This produces costs which we refer to as partial-repetition costs (i.e., the performance deficits with incomplete repetitions of stimulus-feature or stimulus-response combinations as compared to complete repetitions or alternations). 
Partial-repetition costs can be observed if two conditions are met: feature codes need to be integrated in the respective prime trial (a process reflecting binding efficiency); and this created binding needs to be retrieved in the present (probe) trial (a process reflecting the efficiency to control episodic bindings). Interestingly, attempts to dissociate these two processes provided evidence that the binding process proper is more or less automatic (Hommel, 2005). For instance, the degree and strength of binding two given features is independent from the frequency and probability of their co-occurrence (Colzato, Raffone, \& Hommel, 2006; Hommel \& Colzato, 2009) and the availability of attentional resources (Hommel, 2005; Takegata et al., 2005). Nevertheless, bindings involving task-relevant features have a stronger impact on behavior (Hommel, 1998, 2007) and can persist longer (Zmigrod \& Hommel, 2010). Presumably, they are more likely to be retrieved (and/or created) as well as decay slower than irrelevant features. Furthermore, the retrieval process seems to be affected by task instructions and individual differences. For instance, partial-repetition costs have been found to be more pronounced in populations that are unlikely to possess particularly well-functioning binding processes, such as individuals with low fluid intelligence (Colzato, van Wouwe, Lavender, \& Hommel, 2006) and in young children and elderly participants (Hommel, Kray, \& Lindenberger, 2011). This suggests at least some degree of control, assumingly during episodic retrieval. Thus, Given that executivecontrol functions are related to fluid intelligence (Duncan et al., 2000), not fully developed in young age (Hongwanishkul, Happaney, Lee, \& Zelazo, 2005), and impaired in old age (Fisk \& Sharp, 2004), these observations suggest that people differ with respect to the efficiency of managing episodic representations. More specifically, it makes sense to assume that individuals with more efficient executive-control functions like people high in fluid intelligence and younger adults are better able to either inhibit no longer relevant bindings or update those bindings to represent current feature combinations (Colzato, Raffone, et al., 2006).

The possibility that individual differences relate mainly to control over memory traces is also consistent with recent findings of Keizer, Verment, and Hommel (2010), whose participants received neurofeedback to increase cortical gamma synchronization. Such training improved memory retrieval of relevant information in a standard recollection task and reduced partial-repetition costs due to irrelevant bindings. Convergent evidence comes from a study of Hommel, Fischer, Colzato, van den Wildenberg, and Cellini (2011, in press). Consistent with Kofman, Meiran, Greenberg, Balas, and Cohen (2006), Hommel et al. observed that inducing mild stress improved task-switching performance-an indicator of executive-control functioning. Interestingly, the same manipulation also reduced partial repetition costs, suggesting more effective control of episodic retrieval. Thus, although the relationship between binding of stimulus and response features (as in the eventfile task) and control processes is not entirely clear, studies using this task demonstrated that the partial-repetition costs are affected in populations that are impaired with respect to cognitive control or in various situations that associated with lack of cognitive control (Colzato, van Wouwe, et al., 2006; Colzato, Kool, \& Hommel, 2008; Hommel et al., $2011 ; 2011$, in press). Given that performing the event-file task does require, or benefit from, the retrieval of previous episodes, efficient control would result in the prevention of retrieval in the first place or, if that is not possible, in the inhibition of retrieved bindings.

In view of these hints to a link between executive control functions and the management of episodic event files, we considered binding-task performance in individuals suffering from autistic spectrum disorder (ASD) — a disorder that has been related to deficits in both episodic binding (Frith, 2003) and cognitive control (Solomon et al., 2009)-particularly interesting. ASD is one of the most common childhood disorders and characterized by social communication impairment, deficits in language skills, and repetitive behaviors. Various authors have advocated various factors that might account for the disorder, but it is fair to say that there is a rather general agreement that impairments related to executive control functions play a major role (Corbett, Constantine, Hendren, Rocke, \& Ozonoff, 2009; Hill, 2004; Kenworthy, Black, Harrison, Della Rosa, \& Wallace, 2009). Among other things, these impairments are assumed to render ASD patients cognitively less flexible, which would account for both impaired performance in clinical tests like the Wisconsin card sorting task (WCST: Willcutt, Sonuga-Barke, Nigg, \& Sergeant, 2008) and behavioral rigidity in everyday life behavior.

Unfortunately, however, experimental evidence supporting the link between ASD and cognitive flexibility is still scarce and equivocal (Geurts, Corbett, \& Solomon, 2009; Poljac et al., 2010). As suggested by Geurts et al., this might be due to the fact that most clinical tests are rather complex and unlikely to provide process-pure measures of the cognitive processes of interest. For instance, the WCST relies on a good understanding of the task, working memory, learning from feedback, the availability of multiple strategies, and so on. Not all of these abilities and skills are related to the processes targeted by executive-control and flexibility accounts of ASD, so that the outcomes on these kinds of tests are open to various interpretations. Clearly, there is a need for more diagnostic experimental tasks that provide more process-pure measures of cognitive control and flexibility.

In the present study, we investigated whether ASD is associated with impairments in managing episodic event files. More specifically, we were interested to see whether ASD patients are impaired in controlling and flexibly switching between stimulus-response bindings. This would 
fit with the observation of specific deficits in children suffering from ASD in tasks requiring cognitive flexibility, such as Intradimensional/Extradimensional (ID/ED) shift task of the Cambridge Neuropsychological Test Automated Battery (CANTAB) (Ozonoff et al., 2004), or the WCST (for a review, see Hill, 2004). If ASD patients have a deficit in integrating stimulus and/or response features-as some authors have claimed (e.g., Frith, 2003), one would expect ASD patients to show small or no partial-repetition costs. However, if ASD would indeed be associated with poorer event-file management abilities, one would expect ASD patients to show more pronounced partial-repetition costs than control participants do. We tested our hypothesis by comparing the performance of a group of ASD-diagnosed children and a group of normally developing children in a standard event-file task (e.g., Hommel, 1998), which was only slightly adapted for use with children.

\section{Method}

\section{Participants}

The participants in this study included 40 children of age between 11 and 18 years : 20 children (13 males) with autism spectrum disorder (ASD) (age 11-18, mean 15, SD 2.02 ), and 20 (14 males) typically developing children (the control group; age 11-18, mean 15, SD 2.01).

The children with ASD were selected from consecutive referrals to the outpatient and inpatient Department of Child and Adolescent Psychiatry at the University Medical Centre of Utrecht, the Netherlands. In order to qualify for the current study, the ASD participants had to meet the following three criteria: First, a diagnosis of ASD was required. Two certified experienced child psychiatrists diagnosed these participants and needed to reach a consensus on diagnosis. They used DSM-IV criteria for autistic disorder (Diagnostic and Statistical Manual of Mental Disorder, Fourth Edition; American Psychiatric Association, 1994) to evaluate the developmental history of the child as well as current social, emotional, and adaptive functioning. Furthermore, medical records and structured questionnaires completed by the child's parents and teacher(s) were included in the diagnostic process (Child Behavior Checklist: CBCL; and Teacher's Report Form: TRF; Achenbach \& Edelbrock, 1986). Both child psychiatrists observed and interviewed the child in a semi-structured playroom session according to a DSM checklist made available for the Dutch situation. Second, Full-Scale IQs (FSIQ) were required to be 70 or above (Mean IQ 101; SD 9.71), as measured with the Dutch adaptation of the Wechsler Intelligence Scale for Children (Wechsler, 1997). Third, all participants were to have normal or corrected-to-normal vision.
In the healthy controls we included children with the same age range and IQ (there was no significant difference IQ between the groups as measured by $t$-test, $t(38)=2.011$; $p=.051$ ), but without any known neurological or developmental disorders. Their IQ was above 70 (Mean IQ 107; SD 8.81 ) as measured by the Dutch adaptation of the Wechsler Intelligence Scale for Children (Wechsler, 1997), with normal or corrected-to-normal vision.

Finally, the study was conducted in accordance with the declaration of Helsinki and guidelines of the local ethics committee. All parents signed a written consent before participating in the study.

\section{Procedure and design}

The event file task measures binding-related effects, which can be quantified by calculating partial-repetition costs related to combinations of stimulus features (shape and color in our case) and combinations of stimulus features and the response. ${ }^{1}$ One of the perceptual features was task-relevant feature (shape) and the other (color) was the irrelevant feature for the task. To manipulate the repetition versus alternation of stimulus features and responses, the task comprises of pairs of trials with a prime trial $(\mathrm{S} 1 \rightarrow \mathrm{R} 1)$ followed by a probe trial ( $2 \rightarrow \mathrm{R} 2$ ), see Fig. 1 . The probe trial required a manual binary-choice response $(\mathrm{R} 2)$ to the shape of the second stimulus S2 (an apple or a banana). The prime trial required a manual response (R1) to the mere onset of the first stimulus ( $\mathrm{S} 1)$. The correct $\mathrm{R} 1$ was signaled in advance of S1 (through a left- or right-pointing arrowhead), so that $\mathrm{S} 1$ and $\mathrm{R} 1$ could be varied independently, which was necessary to create orthogonal repetitions and alternations of stimulus shape and response. As an additional stimulus feature, color was also varied by presenting the apple or banana in green or yellow (see Colzato, van Wouwe, et al., 2006). Stimulus color could repeat or alternate independently of stimulus shape and responses, thus creating a $2 \times 2 \times 2$-factorial design.

Each trial consisted of a prime-probe pair. The experiment was composed of a practice block with ten practice

\footnotetext{
${ }^{1}$ Partial-repetition costs for a given interaction between factors $\mathrm{X}$ and $\mathrm{Y}$ were calculated as the difference between the RTs/PEs for partial repetitions (feature $\mathrm{X}$ repeated and feature $\mathrm{Y}$ alternated, or vice versa) and the RTs/PEs for complete repetitions and "complete" alternations. E.g., the partial repetition costs in RTs for the shape $\mathrm{X}$ response interaction at a given group would be PRCshapeXresponse $=(\mathrm{RT}$ shape repeated/response alternated $+\mathrm{RT}$ shape alternated/response repeated) $/ 2$ - (RT shape repeated/response repeated + RT shape alternated/ response alternated)/2. Partial repetition costs thus correspond to the 2-way interaction term of the respective features (and are thus immune to possible, but theoretically less relevant, main effects of feature repetition); a value close to zero means that the repetition effects of the two given features do not interact; a value greater than zero indicates a "binding-type" interaction of the sort described in the text.
} 
Fig. 1 Sequence of events in the event file task. A visual response cue signaled a left or right response (R1) that was to be delayed until presentation of the first stimulus $\mathrm{S} 1$ ( $\mathrm{S} 1$ is used as a detection signal for $\mathrm{R} 1$ ). The second stimulus $\mathrm{S} 2$ appeared $1,000 \mathrm{~ms}$ after $\mathrm{S} 1$. S2 signaled $\mathrm{R} 2$, a speeded left or right response according to the shape

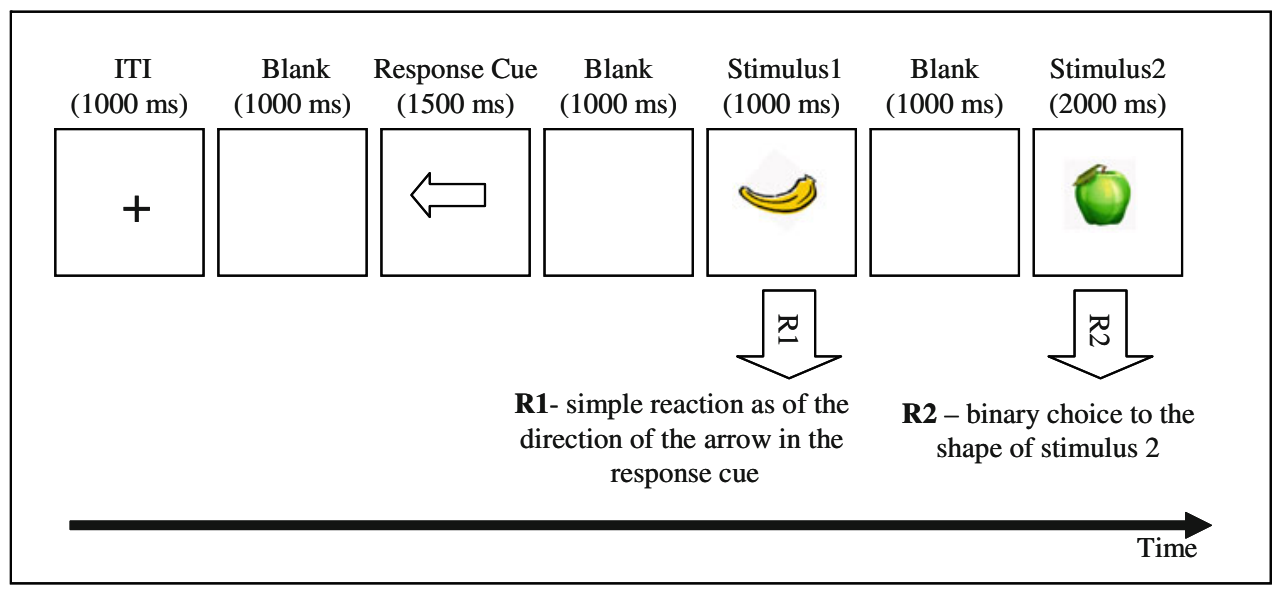

Table 1 Means of mean reaction times for responses to stimulus 2 $\left(\mathrm{RT}_{\mathrm{R} 2}\right.$ in $\mathrm{ms}$ ) and $\mathrm{SE}$ in parenthesis, as a function of group (ASD children vs. control-typically developing children), the relationship be-

\begin{tabular}{|c|c|c|c|c|c|}
\hline \multirow[t]{2}{*}{ Group } & \multicolumn{2}{|c|}{ Response repeated } & \multicolumn{2}{|c|}{ Response alternated } & \multirow{2}{*}{$\begin{array}{l}\text { Partial repetition } \\
\text { costs }\end{array}$} \\
\hline & Shape repeated & Shape alternated & Shape repeated & Shape alternated & \\
\hline \multicolumn{6}{|l|}{ RTs (ms) } \\
\hline ASD & $518(20)$ & $649(24)$ & $591(24)$ & $549(24)$ & 86 \\
\hline Control & $576(20)$ & $635(24)$ & $616(24)$ & $568(24)$ & 53 \\
\hline \multicolumn{6}{|l|}{ Errors (\%) } \\
\hline ASD & $5.7(0.8)$ & $18.1(1.9)$ & $14.5(1.6)$ & $4.5(0.8)$ & 11.2 \\
\hline Control & $1.3(0.8)$ & $6.1(1.9)$ & $9.6(1.6)$ & $1.6(0.8)$ & 6.4 \\
\hline \multirow[t]{2}{*}{ Group } & \multicolumn{2}{|c|}{ Response repeated } & \multicolumn{2}{|c|}{ Response alternated } & \multirow{2}{*}{$\begin{array}{l}\text { Partial repetition } \\
\text { costs }\end{array}$} \\
\hline & Color repeated & Color alternated & Color repeated & Color alternated & \\
\hline \multicolumn{6}{|l|}{ RTs (ms) } \\
\hline ASD & $580(22)$ & $587(21)$ & $575(24)$ & $566(23)$ & 8 \\
\hline Control & $600(22)$ & $611(21)$ & $592(24)$ & $592(23)$ & 5 \\
\hline \multicolumn{6}{|l|}{ Errors $(\%)$} \\
\hline ASD & $11.4(1.3)$ & $12.4(1.4)$ & $10.2(1.2)$ & $8.7(1.2)$ & 1.2 \\
\hline Control & $3.6(1.3)$ & $3.8(1.4)$ & $7.3(1.2)$ & $4.0(1.2)$ & 1.8 \\
\hline
\end{tabular}

The rightmost column gives the partial repetition costs (see footnote 1), which differed significantly in response-shape between the two groups, $p<.005$, both in reaction times and error rates

trials, which were not further analyzed, and an experimental block with 196 experimental trials. The order of the trials was randomized but all eight conditions appeared equally often. Half of the participants responded to the apple and the banana by pressing on the left and right key press, respectively, while the other half received the opposite mapping. The participants were asked to respond as quickly and accurately as possible.

\section{Results}

Trials with incorrect $\mathrm{R} 1$ responses $(0.75 \%)$, as well as missing $(\mathrm{RT}>1,500 \mathrm{~ms})$ or anticipatory $(\mathrm{RT}<100 \mathrm{~ms}) \mathrm{R} 2$ tween the responses ( $\mathrm{R} 1$ and $\mathrm{R} 2$ ), and the relationship between the stimuli features (S1 and S2) for shape and color 
strategy. There was a significant main effect of shape repetition in RTs, $F(1,38)=13.54, p<.001$, due to faster responses to repeated $(581 \mathrm{~ms})$ than alternated shapes $(605 \mathrm{~ms})$. This effect was modified by group, $F(1,38)=$ $5.20, p<.05$; separate ANOVAs, split by group, revealed that it was statistically significant only in the ASD group, $F(1,19)=13.207, p<.005$, where responses were slower to shape alternation $(596 \mathrm{~ms})$ than to shape repetition $(556 \mathrm{~ms})$, indicating slower adaptation to alternations. These results are in line with studies showing that ASD children demonstrate deficits in adaptive skills (e.g., Kanne et al., 2011; Paul et al., 2004) and repetitive behaviors (South, Ozonoff, \& Mcmahon, 2007).

There were significant interactions between shape repetition and response repetition in RTs, $F(1,38)=113.77$, $p<.0001$; and PEs, $F(1,38)=61.08, p<.0001$. These findings followed the common pattern with worse performance if only one of the features (shape or response) is repeated while the other is not, as compared with complete repetitions or alternations (see Hommel, 1998). In addition, there was a significant interaction between color, the irrelevant feature, and the response in PEs, $F(1,38)=9.87, p<.005$, showing that the response was more accurate for total repetition or total alternation of the response and the color than partial repetition (see Table 1).

More importantly for our study, the response-shape interaction was further modified by group in both RTs, $F(1,38)=4.478, p<.05$; and PEs, $F(1,38)=6.82, p<.05$ (see Fig. 2). This was due to more pronounced interactions in children with ASD than in typically developing children. In contrast, group was not involved in either the three-way interactions with shape and color or with color and response, all $F s(1,38)<1$, or the four-way interaction, $F(1,38)=0.51$, $p=.48$, and $F(1,38)=2.65, p=.11$, for RTs and PEs, respectively, indicating that the impact of group is restricted to effects of features from relevant dimensions.

To further analyze the response-shape interaction, we calculated partial repetition costs (see footnote 1) for RTs and PEs and ran an ANOVA with group type. There were reliable effects of group in RTs: $\mathrm{F}(1,38)=4.47 p<.05$, and PEs: $\mathrm{F}(1,38)=6.83, p<.05$, indicating higher costs associated with shape-response integration for ASD than the control group (see Fig. 3).

As the experiment was relatively long, participants could develop particular strategies to deal with the task, especially with its relevant aspects (i.e., shape and response features) which might have changed the respective effects over time. To test this possibility and to see whether it might have emerged in the two groups differently, we split the data into a first and second half, calculated (responseshape) partial repetition costs for the two practice levels for each group in RTs and PEs, and ran an ANOVA with practice level and group type as factors. However, there were no

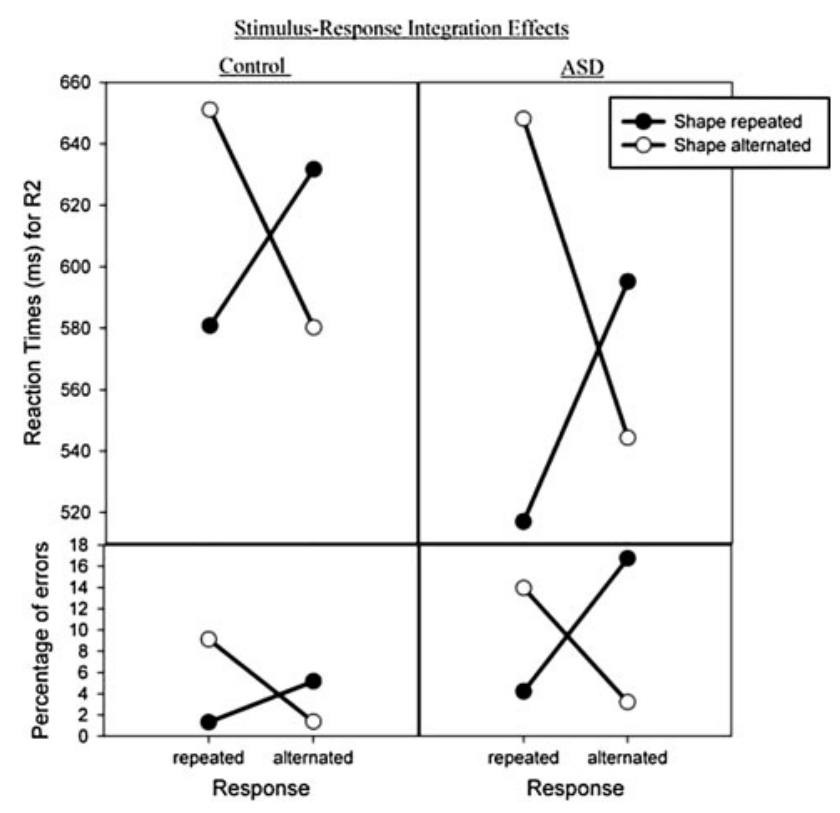

Fig. 2 Mean reaction times and error percentages (on R2) for repetition versus alternation of the shape as a function of response repetition versus alternation and the group

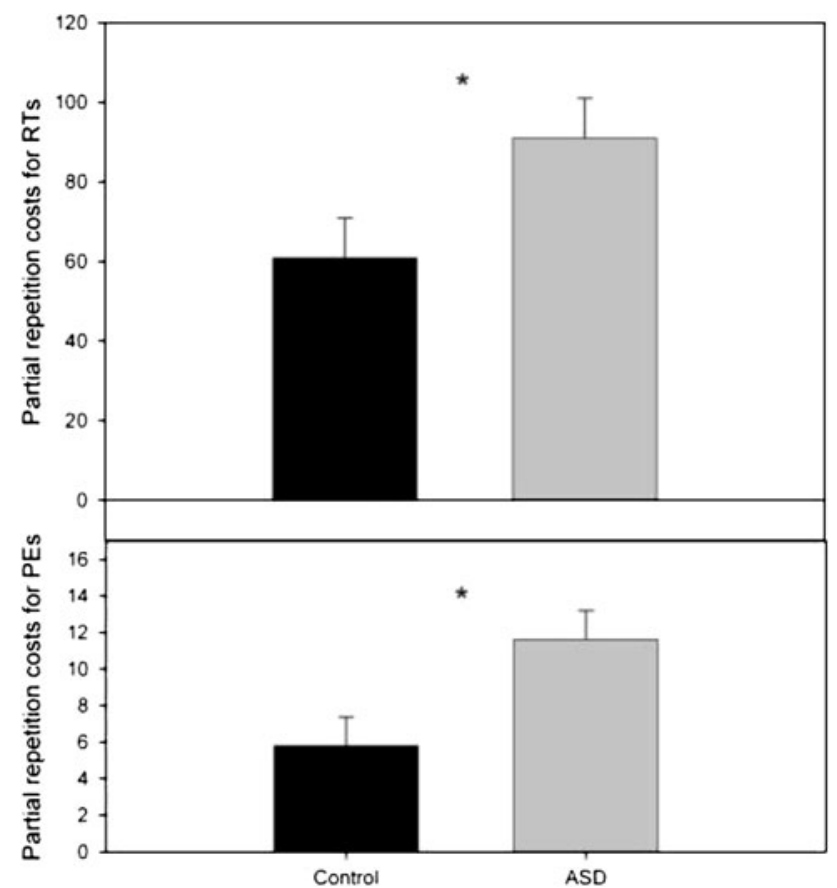

Fig. 3 Effects indicating shape-response partial repetition costs (footnote 1 ) in reaction times and error rates (on R2), for the ASD and control groups. ${ }^{*} p<.005$

significant main effects of practice level in RTs and PEs (Fs $<1$ ) or interactions between group and practice level (Fs $<1$ ). This does not provide evidence that all or some of the participants developed particular strategies to deal with the task over time, at least not in a systematic fashion. 


\section{Discussion}

The aim of this study was to investigate whether children suffering from ASD would show a specific deficit in a task tapping into the handling of episodic event files, that is, of bindings between codes that represent the features of experienced objects and stimulus-response episodes (Hommel, 1998, 2004). Both normally developing controls and the ASD group showed partial-repetition costs for combinations of the two task-relevant stimulus and response features: stimulus shape and response location. It is known that task relevance modulates feature-integration effects (e.g., Hommel, 1998; Hommel \& Colzato, 2004) so that it is not surprising that the reliable effects were mainly restricted to the features that mattered for the task. More interesting, however, is that these effects were observed in both groups. Given that partial-repetition costs in S2-R2 performance can only occur if the respective features are integrated when processing $\mathrm{S} 1$ and $\mathrm{R} 1$, this observation implies that binding as such does not seem to be impaired in ASD. This does not seem to fit with the claim that ASD is associated with difficulties in feature integration (e.g., Frith, 2003).

Importantly, the aftereffects of binding were larger but not smaller in the ASD group (see Fig. 3), suggesting that ASD children are impaired in managing of episodic representations. That is, both healthy controls and children suffering from ASD seem to spontaneously integrate stimulus-response episodes and automatically retrieve traces of these episodes when facing a similar, that is, feature-overlapping episode thereafter (see Fig. 2). However, healthy controls seem to be more efficient in preventing these traces from affecting ongoing processes and/or updating the traces if they do not fit with the current feature combinations, reflecting a specific deficit in cognitive control in ASD. We found no evidence that the after-effects of binding the relevant task features change over time or that such changes differed between the two groups, suggesting that the group differences are relatively stable. These findings are in line with the recent observations that partial-repetition costs are more pronounced in individuals with low fluid intelligence (Colzato, van Wouwe, et al., 2006) and in young children and elderly participants, as compared with young adults (Hommel et al., 2011). Taken together, these findings suggest that less efficient control functions increase the impact of previously created feature bindings.

Studies have demonstrated ASD-related impairments in various executive functions (Hill, 2004; Ozonoff et al., 2004; Solomon, Ozonoff, Cummings, \& Carter, 2008). Specifically, deficits in cognitive control and flexibility have long been associated with ASD (Geurts et al., 2009). Numerous studies have shown such deficits in various neuropsychological tests, such as the WCST task (Hill, 2004), the ID/ED shift task (Ozonoff et al., 2004), and the preparing to overcome prepotency ("POP") task (Solomon et al., 2008, 2009). The present study provides additional evidence for ASD-related impairments in cognitive control and flexibility and points to a specific deficit with regard to the flexible adjustment of perception-action episodes. Hence, there are reasons to assume that partial-repetition costs provide additional measurement of flexibility, at least with respect to the updating of cognitive representations.

Converging evidence for an interesting theoretical and empirical link between ASD, control functions, and partialrepetition costs comes from research on the neuromodulation of the underlying cognitive processes and in particular from the fact that they all seem to rely on prefrontal dopaminergic pathways and their interaction with striatal dopaminergic pathways. Atypical dopaminergic activity is associated with ASD along with ADHD and schizophrenia (Previc, 1999, 2007). Considering the comorbidity between ASD and ADHD, it seems plausible that a dopaminerelated abnormality is the common source for the similar symptoms in these two disorders (Gillberg \& Billstedt, 2000). In addition, some of the behavioral symptoms in ASD children were reduced by administrating risperidone (a dopamine-receptor antagonist; McCracken et al., 2002). Moreover, ASD is considered as one of the most highly heritable developmental disorder, and a number of genes linked to it (see: Yonan et al., 2003) are associated with dopamine, such as DBH (Robinson, Schutz, Macciardi, White, \& Holden, 2001).

The dopaminergic system is also involved in a number of executive control functions, such as planning, working memory, or temporal sequencing (for a review, see Previc, 1999). More relevant to our study, there is compelling evidence that the dopaminergic system is important for mental flexibility and cognitive shifting operations. For instance, older adults show declines in dopaminergic transmission related to D1 (Rinne, Lonnberg, \& Marjamaki, 1990; Suhara et al. 1991) and D2 receptors (Rinne et al., 1990; Volkow et al., 1996), and these declines are associated with poor performance in many neuropsychological controlrelated tests, such as the Stroop task, the WCST, and others (Volkow et al., 1998). This decline in cognitive ability can be corrected by administrating dopaminergic agonist such as Piribedil (Ollat, 1992). Furthermore, flexibility is improved by inducing positive affect (Dreisbach, 2006; van Wouwe, Band, \& Ridderinkhof, 2011), which is assumed to induce temporary increases of the dopamine level (Ashby, Isen, \& Turken, 1999; Dreisbach \& Goschke, 2004). Thus, cognitive control and flexibility in particular appear to be modulated by dopamine.

Given that both ASD and cognitive flexibility seem to depend on dopaminergic pathways, it is interesting that the same seems to be true for partial-repetition costs. For 
instance, these costs are systematically modulated by affect (Colzato, Wouwe, \& Hommel, 2007a) and related to individual differences in the spontaneous eyeblink rate (Colzato, Wouwe, \& Hommel 2007b), a clinical marker for the level of dopaminergic functioning (Blin, Masson, Azulay, Fondarai, \& Serratrice, 1990; Kleven \& Koek, 1996). Moreover, aftereffects of stimulus-response bindings are affected by stress (Colzato et al., 2008) and the use of cannabis, but not cocaine (Colzato \& Hommel, 2008), suggesting that it is mainly dopaminergic D1 receptors that are involved, but not D2 receptors. Given that D1, but not D2, receptors are dominant in the mesocortical dopaminergic pathways, which are also assumed to drive executive control functions including working memory (e.g., Arnsten \& Goldman-Rakic, 1998), these observations provide converging evidence for a link between ASD, executive control, and the management of episodic feature bindings.

To conclude, meeting the challenges a dynamic environment poses requires the human brain to find a balance between stability - as in integrating and keeping integrated the features of perceived event along with the actions they afford-and flexibility - as in updating, managing, and adapting integrated representations. Distortions of this balance can cause inflexibility and maladaptive behavior as can be seen in developmental disorders (Previc, 2007), substance abuse (Colzato \& Hommel, 2008; Previc, 2007), and stress-related behaviors (Arnsten \& Goldman-Rakic, 1998; Colzato et al., 2008). The present study provides evidence that ASD is associated with a specific deficit in updating episodic stimulus-response representations. From a general neuroscientific perspective, this implies that ASD is targeting processes and functions that are crucial not so much for the creation of episodic bindings but for their cognitive control and updating. Accordingly, ASD can serve as a useful "model" for the breakdown of the control of retrieval from episodic memory. From a neuropathological perspective, it is interesting that even the relatively simple task we used to assess aftereffects of feature binding captures the essence of processes that also impair performance in more complex experimental tasks and neuropsychological tests.

Open Access This article is distributed under the terms of the Creative Commons Attribution Noncommercial License which permits any noncommercial use, distribution, and reproduction in any medium, provided the original author(s) and source are credited.

\section{References}

Achenbach, T. M., \& Edelbrock, C. S. (1986). Manual for the Teacher's Report Form and Teacher Version of the Child Behavior Profile. Burlington, VT: University of Vermont, Department of Psychiatry.

American Psychiatric Association. (1994). Diagnostic and statistical manual of mental disorders (4th ed.). Washington, DC: Author.
Arnsten, A. F. T., \& Goldman-Rakic, P. S. (1998). Noise stress impairs prefrontal cortical cognitive function in monkeys: Evidence for a hyperdopaminergic mechanism. Archives of General Psychiatry, $55,362-368$.

Ashby, F. G., Isen, A. M., \& Turken, U. (1999). A neuropsychological theory of positive affect and its influence on cognition. Psychological Review, 106, 529-550.

Blin, O., Masson, G., Azulay, J. P., Fondarai, J., \& Serratrice, G. (1990). Apomorphine-induced blinking and yawning in healthy volunteers. British Journal of Clinical Pharmacology, 30, 769-773.

Colzato, L. S., \& Hommel, B. (2008). Cannabis, cocaine, and visuomotor integration: Evidence for a role of dopamine D1 receptors in binding perception and action. Neuropsychologia, 46, 15701575 .

Colzato, L. S., Kool, W., \& Hommel, B. (2008). Stress modulation of visuomotor binding. Neuropsychologia, 46, 1542-1548.

Colzato, L. S., Raffone, A., \& Hommel, B. (2006a). What do we learn from binding features? Evidence for multilevel feature integration. Journal of Experimental Psychology: Human Perception and Performance, 32, 705-716.

Colzato, L. S., van Wouwe, N. C., \& Hommel, B. (2007a). Feature binding and affect: Emotional modulation of visuo-motor integration. Neuropsychologia, 45, 440-446.

Colzato, L. S., van Wouwe, N. C., \& Hommel, B. (2007b). Spontaneous eye-blink rate predicts the strength of visuomotor binding. Neuropsychologia, 45, 2387-2392.

Colzato, L. S., van Wouwe, N. C., Lavender, T. J., \& Hommel, B. (2006b). Intelligence and cognitive flexibility: Fluid intelligence correlates with feature "unbinding" across perception and action. Psychonomic Bulletin \& Review, 13, 1043-1048.

Corbett, B. A., Constantine, L. J., Hendren, R., Rocke, D., \& Ozonoff, S. (2009). Examining executive functioning in children with autism spectrum disorder, attention deficit hyperactivity disorder and typical development. Psychiatry Research, 166, 210-222.

DeYoe, E. A., \& van Essen, D. C. (1988). Concurrent processing streams in monkey visual cortex. Trends in Neurosciences, 11, 219-226.

Dreisbach, G. (2006). How positive affect modulates cognitive control: The costs and benefits of reduced maintenance capability. Brain and Cognition, 60, 11-19.

Dreisbach, G., \& Goschke, T. (2004). How positive affect modulates cognitive control: Reduced perseveration at the cost of increased distractibility. Journal of Experimental Psychology: Learning, Memory, and Cognition, 30, 343-353.

Duncan, J., Seitz, R. J., Kolodny, J., Bor, D., Herzog, H., Ahmed, A., et al. (2000). A neural basis for general intelligence. Science, 289, 457-460.

Fisk, J. E., \& Sharp, C. A. (2004). Age-related impairment in executive functioning: Updating, inhibition, shifting, and access. Journal of Clinical and Experimental Neuropsychology, 26, 874-890.

Frith, U. (2003). Autism: Explaining the enigma (2nd ed. ed.). Oxford: Blackwell.

Geurts, H. M., Corbett, B., \& Solomon, M. (2009). The paradox of cognitive flexibility in autism. Trends in Cognitive Sciences, 13, 74-82.

Gillberg, C., \& Billstedt, E. (2000). Autism and Asperger syndrome: Coexistence with other clinical disorders. Acta Psychiatrica Scandinavica, 102, 321-330.

Hill, E. L. (2004). Evaluating the theory of executive dysfunction in autism. Developmental Review, 24, 189-233.

Hommel, B. (1998). Event files: evidences for automatic integration of stimulus-response episodes. Visual Cognition, 5, 183-216.

Hommel, B. (2004). Event files: feature binding in and across perception and action. Trends in Cognitive Sciences, 8, 494-500.

Hommel, B. (2005). How much attention does an event file need? Journal of Experimental Psychology: Human Perception and Performance, 31, 1067-1082. 
Hommel, B. (2007). Feature integration across perception and action: Event file affect response choice. Psychological Research, 7, 42-63.

Hommel, B., \& Colzato, L. S. (2004). Visual attention and the temporal dynamics of feature integration. Visual Cognition, 11, 483-521.

Hommel, B., \& Colzato, L. S. (2009). When an object is more than a binding of its features: Evidence for two mechanisms of visual feature integration. Visual Cognition, 17, 120-140.

Hommel, B., Fischer, R., Colzato, L. S., van den Wildenberg, W. P. M., \& Cellini, C. (2011). The effect of fMRI (noise) on cognitive control. Journal of Experimental Psychology: Human Perception and Performance (in press).

Hommel, B., Kray, J., \& Lindenberger, U. (2011). Feature integration across the lifespan: Stickier stimulus-response bindings in children and older adults. Frontiers in Psychology, 2, 268.

Hongwanishkul, D., Happaney, K. R., Lee, W. S. C., \& Zelazo, P. D. (2005). Assessment of hot and cool executive function in young children: Age-related changes and individual differences. Developmental Neuropsychology, 28, 617-644.

Kahneman, D., Treisman, A., \& Gibbs, B. J. (1992). The reviewing of object files: Object specific integration of information. Cognitive Psychology, 24, 175-219.

Kanne, S. M., Gerber, A. J., Quirmbach, L. M., Sparrow, S. S., Cicchetti, D. V., \& Saulnier, C. A. (2011). The role of adaptive behavior in autism spectrum disorders: Implications for functional outcome. Journal of Autism and Developmental Disorders, 41, 1007-1018.

Keizer, A. W., Verment, R. S., \& Hommel, B. (2010). Enhancing cognitive control through neurofeedback: A role of gamma-band activity in managing episodic retrieval. Neuroimage, 49, 34043413.

Kenworthy, L., Black, D. O., Harrison, B., Della Rosa, A., \& Wallace, G. L. (2009). Are executive control functions related to autism symptoms in high-functioning children? Child Neuropsychology, $15,425-440$

Kleven, M. S., \& Koek, W. (1996). Differential effects of direct and indirect dopamine agonists on eye blink rate in cynomolgus monkeys. Journal of Pharmacology and Experimental Therapeutics, $279,1211-1219$

Kofman, O., Meiran, N., Greenberg, E., Balas, M., \& Cohen, H. (2006). Enhanced performance on executive function tasks associated with examination stress: Evidence from task switching and Stroop paradigms. Cognition and Emotion, 20, 577-595.

McCracken, J. T., McGough, J., Shah, B., Cronin, P., Hong, D., Aman, M. G., et al. (2002). Risperidone in children with autism and serious behavioral problems. New England Journal of Medicine, 347, 314-321.

Mondor, T. A., Hurlburt, J., \& Thorne, L. (2003). Categorizing sounds by pitch: Effects of stimulus similarity and response repetition. Perception and Psychophysics, 65, 107-114.

Ollat, H. (1992). Dopaminergic insufficiency reflecting cerebral aging: Value of a dopaminergic agonist, piribedil. Journal of Neurology, 239, S13-S16.

Ozonoff, S., Cook, I., Coon, H., Dawson, G., Joseph, R. M., Klin, A., et al. (2004). Performance on Cambridge Neuropsychological Test Automated Battery subtests sensitive to frontal lobe function in people with autistic disorder: Evidence from the Collaborative Programs of Excellence in Autism network. Journal of Autism and Developmental Disorders, 34, 139-150.

Paul, R., Miles, S., Cicchetti, D., Sparrow, S., Klin, A., Volkmar, F., et al. (2004). Adaptive behavior in autism and pervasive developmental disorder-not otherwise specified: Microanalysis of scores on the Vineland Adaptive Behavior Scales. Journal of Autism and Developmental Disorders, 34, 223-228.
Poljac, E., Simon, S., Ringlever, L., Kalcik, D., Groen, W. B., Buitelaar, J. K., et al. (2010). Impaired task switching performance in children with dyslexia but not in children with autism. Quarterly Journal of Experimental Psychology, 63, 401-416.

Previc, F. H. (1999). Dopamine and the origins of human intelligence. Brain and Cognition, 41, 299-350.

Previc, F. H. (2007). Prenatal influences on brain dopamine and their relevance to the rising incidence of autism. Medical Hypotheses, $68,46-60$.

Rinne, J. O., Lonnberg, P., \& Marjamaki, P. (1990). Age-dependent decline in human brain dopamine D1 and D2 receptors. Brain Research, 508, 349-352.

Robinson, P. D., Schutz, C. K., Macciardi, F., White, B. N., \& Holden, J. J. A. (2001). Genetically determined low maternal serum dopamine beta-hydroxylase levels and the etiology of autism spectrum disorders. American Journal of Medical Genetics, 100, 30-36.

Solomon, M., Ozonoff, S. J., Cummings, N., \& Carter, C. S. (2008). Cognitive control in autism spectrum disorders. International Journal of Developmental Neuroscience, 26, 239-247.

Solomon, M., Ozonoff, S. J., Ursu, S., Ravizza, S., Cummings, N., Ly, S., et al. (2009). The neural substrates of cognitive control deficits in autism spectrum disorders. Neuropsychologia, 47, 2515-2526.

South, M., Ozonoff, S., \& Mcmahon, W. M. (2007). The relationship between executive functioning, central coherence, and repetitive behaviors in the high-functioning autism spectrum. Autism, 11, 437-451.

Suhara, T., Fukuda, H., Inoue, O., Itoh, T., Suzuki, K., Yamasaki, T., et al. (1991). Age-related changes in human D1 dopamine receptors measured by positron emission tomography. Psychopharmacology, 103, 41-45.

Takegata, R., Brattico, E., Tervaniemi, M., Varyagina, O., Näätänen, R., \& Winkler, I. (2005). Preattentive representation of feature conjunctions for concurrent spatially distributed audition objects. Cognitive Brain Research, 25, 169-179.

van Wouwe, N. C., Band, G. P. H., \& Ridderinkhof, K. R. (2011). Positive affect modulates flexibility and evaluative control. Journal of Cognitive Neuroscience, 23, 524-539.

Volkow, N. D., Gur, R. C., Wang, G. J., Fowler, J. S., Moberg, P. J., Ding, Y. S., et al. (1998). Association between decline in brain dopamine activity with age and cognitive and motor impairment in healthy individuals. American Journal of Psychiatry, 155, 344 349.

Volkow, N. D., Wang, G. J., Fowler, J. S., Logan, J., Gatley, S. J., MacGregor, R. R., et al. (1996). Measuring age-related changes in dopamine D-2 receptors with C-11-raclopride and F-18-N-methylspiroperidol. Psychiatry Research: Neuroimaging, 67, 11-16.

Wechsler, D. (1997). WAIS-III Dutch Translation. Lisse: Swets \& Zeitlinger.

Willcutt, E. G., Sonuga-Barke, E. J., Nigg, J. T., \& Sergeant, J. A. (2008). Recent developments in neuropsychological models of childhood psychiatric disorders. Advances in Biological Psychiatry, 24, 195-226.

Yonan, A. L., Alarcón, M., Cheng, R., Magnusson, P. K., Spence, S. J., Palmer, A., et al. (2003). A genomewide screen of 345 families for autism-susceptibility loci. American Journal Human Genetics, 73, 886-897.

Zmigrod, S., \& Hommel, B. (2009). Auditory event files: Integrating auditory perception and action planning. Attention, Perception, and Psychophysics, 71, 352-362.

Zmigrod, S., \& Hommel, B. (2010). Temporal dynamics of unimodal and multimodal feature binding. Attention, Perception, \& Psychophysics, 72, 142-152.

Zmigrod, S., Spapé, M., \& Hommel, B. (2009). Intermodal event files: Integrating features across vision, audition, taction, and action. Psychological Research, 73, 674-684. 